\title{
Money-market segmentation in the Euro area: What has changed during the turmoil?
}

\author{
Paolo Zagaglia*
}

April 23, 2009

\begin{abstract}
I study how the pattern of segmentation in the Euro area money market has been affected by the recent turmoil in financial markets. I use nonparametric estimates of realized volatility to test for volatility spillovers between rates at different maturities. For the pre-turmoil period, exogeneity tests from VAR models suggest the presence of a transmission channel from longer maturities to the overnight. This disappears in the subsample starting in August 92007. Quantile measures of comovements in volatility report evidence of an increase in contagion within the longer end of the money market curve.
\end{abstract}

Keywords: Money market, high-frequency data, time-series methods.

JEL Classification: C22, E58.

${ }^{*}$ This is a revised version of a Bank of Finland Working Paper distributed with the same title. I am deeply grateful to Stefano Nardelli for his advice and for providing the dataset, and to Juha Kilponen and Jouko Vilmunen for many helpful discussions. One anonymous referee provided constructive comments. The views expressed in this paper are solely those of the author and should not attributed to the Bank of Finland. 


\section{Introduction}

The decisions of the Governing Council of the European Central Bank on the key interest rate are implemented through money market channels. The monetary policy stance is signalled by setting the minimum bid rate, which is the lower limit on the price paid by private banks at the weekly main refinancing operations of the ECB. These operations take the form of variable rate tenders where bids are allotted pro rata. As an alternative source, banks can gather liquidity also through the interbank market. In order to drive market rates to a desired level, the European Central Bank conducts open market operations. Although explicit targets are not announced, the practice suggests that the ECB aims to stabilize short term rates around the policy rate.

In this context, the overnight segment of the interbank money market plays a key role in signalling the policy stance. As noticed by the ECB (2005b, 2006), not only is it crucial for the volatility of the overnight rates to remain low. ${ }^{1}$ ECB (2005b) points out that the monetary policy stance should be affected only by the decision on the key interest rates. The so-called proposition of neutrality is a backbone of the conduct of liquidity policy of the ECB, which is best explained by Trichet (2007)

"I would emphasize that our primary mandate calls for our monetary policy stance to deliver price stability in the medium term. Once the level of interest rates is decided we have the responsibility to ensure the smooth functioning of the segment of the money market that we influence.

The two responsibilities are clearly separated and should not be mixed."

In other words, the provision of liquidity is guided solely by the need to smooth out liquidity shocks, and interest rate expectations at long maturities should be decoupled from the evolution of the daily liquidity conditions.

The neutrality of the liquidity policy is discussed in a number of contributions such as Alonso and Blanco (2005), ECB (2005b, 2007) and Durré and Nardelli (2008). Alonso and Blanco (2005) estimate univariate models of conditional volatility where interactions between rates at different maturities are modelled through dummy variables. They find evidence of interactions generated in a sample until November 2003. Durré and Nardelli (2008) stress the role of the microstructure of the money market. They use high frequency data to compute nonparametric estimates of the daily realized volatility. Estimated impulse responses in vector

\footnotetext{
${ }^{1}$ This has also provided a reason for the changes to the operational framework introduced in March 2004. In order to prevent excessive bidding from taking place during the main refinancing operations, the Governing Council decided to change the timing of the reserve maintenance period, and to shorten the maturity of the main refinancing operations to one week. ECB (2005a, 2006) show that the operational changes have reduced the volatility of the overnight interest rate.
} 
autoregressions suggest that the liquidity management carried out by the ECB does not affect the transmission mechanism along the money market yield curve. Zagaglia (2008) studies the transmission of volatility shocks arising from the longer end of the money market maturity curve to the short end. The results suggest that the reform of March 2004 has insulated the overnight segment from spillovers in volatility arising from rates of up to 6 months of maturity.

In this paper, I investigate the overall pattern of transmission of volatility shocks along the money market term structure, running also from the long to the overnight end of the curve. This is the so-called 'segmentation' of the money market. There are two aspects of segmentation that bear policy relevance. As suggested earlier, the first one has to do with the transmission of volatility shocks. The eventual presence of spillovers from long maturities to the overnight can shed light on the role of liquidity policy, and on its ability to control the overnight segment effectively. On the other hand, the transmission of volatility across money market rates at long maturities can affect the stability of expectations formation, thus adding a potential source of noise to the monetary transmission mechanism. The second dimension has to do with the ability of monetary policy to steer average interest rates at horizons beyond the overnight. Although the ability of the ECB to control the stability of monetary policy and inflationary expectations embedded in the money market curve has received no academic attention, here I focus on the volatility aspect.

The key economic event that has characterized the world economy since 2007 is the eruption of a 'turmoil' in financial markets. The turmoil started from concerns related to the US subprime market in June 2007. This led to a reassessment of credit and liquidity risk along a large number of asset classes. The lack of confidence on the evaluation of bonds related to subprime loans has spilled over into the money markets around the globe. The result became evident on August 9 2007, when liquidity dried up both in the overnight and in the segments at longer maturities. The ECB, the Federal Reserve System and the Bank of Japan provided emergency liquidity to the markets.

Academic contributions on the impact of turmoil on the Euro area money market have been limited. The only exception is Idier and Nardelli (2008), who study the transmission of information in the overnight market. Against this background, I investigate how the turmoil has affected the existing pattern of money market segmentation. I use the nonparametric estimates of volatility of Durré and Nardelli (2008) to test for volatility spillovers between rates of different maturities through two different statistical methods. I compute tests for block exogeneity and Granger causality in vector autoregressions with realized volatilities. To investigate the robustness of the results, I also apply the semiparametric tests for 'contagion' of 
Cappiello, Gerard and Manganelli (2005). These are capable of accounting properly for the tail behaviour generated by extreme events, like the turmoil.

For the pre-turmoil period, the exogeneity tests suggest the presence of a transmission channel from longer maturities to the overnight. This channel disappears in the subsample starting in August 9 2007, indicating that the turmoil has increased the degree of segmentation of the money market. The results of the semiparametric tests of Cappiello, Gerard and Manganelli (2005) report evidence of an increase in volatility contagion within the longer end of the money market curve. However this takes place in the lower tail of the empirical distributions.

This paper is organized as follows. Section 2 presents a selected overview of the main institutional aspects of the Euro area money market. Section 3 summarizes the events leading to the spillover of the financial markerts turmoil into the money market. Section 4 describes the dataset on realized volatilities, and outlines the testing frameworks used in the empirical exercise. The results are discussed in section 5. Section 6 concludes.

\section{An overview of the structure of the Euro area money market}

The Member States share a unified money market where the implementation of monetary policy is decentralized and carried out by national central banks. The functioning of the operational framework is grounded on two aspects. First, the ECB carries out a number of open market operations including the weekly main refinancing operations and the longer term refinancing operations. A total of 1967 financial institutions across the Euro area are eligible to borrow against collateral. However, as noted by Durré and Nardelli (2008), the effective number of participants is rather limited. Under the operational framework, banks face also compulsory reserve requirements that are held at national central banks over a 'maintenance period', which lasts four weeks on average. Since the requirement works on 'average', banks can smooth out the impact of liquidity shocks on their funding needs, thus stabilizing the money market at the shortest maturities. ${ }^{2}$

The money market is divided into cash and derivatives segments. Banks use the unsecured market for the management of their contingent liquidity needs. Transactions take place both over-the-counter (direct dealing) and through electronic centralized platform. An example of the latter is represented by e-MID, which is

\footnotetext{
${ }^{2}$ The interested reader can refer to ECB (2004) for a thorough description of the operating framework.
} 
run by e-MID S.p.A. Milan. ${ }^{3}$ It should be pointed out, however, that electronic trading accounts only for $17 \%$ of market activity in unsecured markets (see Idier and Nardelli, 2008). This is due both to institutional factors that limit the access to trading on electronic platforms, ${ }^{4}$ and to the fact that reputation matters for contracting schemes that require no collateral.

Although strongly concentrated on overnight maturity, the unsecured markets provide rates for maturities from the overnight up to one year. The main benchmarks are the Euro overnight index average (Eonia) and the Euro interbank offered rate (Euribor). The Eonia consists of the weighted average of unsecured loans provided by a panel of banks. The Euribor, instead, is the reference rate on the longer maturities. The cash markets also include forms of collateralised lending through repo and swaps against foreign currencies. Finally, the derivatives segment includes trading on Eonia swaps and Euribor futures.

The structure of the money market defines the functioning of the monetary transmission mechanism. The weekly main refinancing operations have a direct impact on the overnight markets. At the same time, both the allotment outcomes from the main refinancing operations, and markets' expectations of future policy rates affect the entire maturity structure of the money market. The prescription of neutrality of the liquidity policy of the ECB indicates that the volatility of the overnight segment is not to spill over into the longer end of the maturity structure. Notwithstanding, changes in the average rates ought to be transmitted throughout the entire maturity spectrum.

\section{A short anatomy of the turmoil}

The first semester of 2007 was characterized by a rather favourable environment for financial markets. A strong macroeconomic outlook provided the background for expected buoyant profitability of the corporate sector. Doubts about the health of the US mortgage markets were raised in June 2007. Investors awareness focused on 'subprime' loans, mainly consisting of residential loans provided to distressed borrowers.

Table 1 reports the timeline of major events. On June 15, Moody's announced negative ratings on 267 securities backed by subprime mortgages. On June 20, two Bear Stearns hedge funds reported large losses related to the subprime market, and ended up almost closed. A number of negative news followed. On July 10, Standard and Poor's assigned negative ratings to a large fraction of the loans of one of the

\footnotetext{
${ }^{3}$ Beaupain and Durré (2008) study transaction pattern in the overnight market of e-MID.

${ }^{4}$ Only banks with a net worth of 10 million USDs at least can participate in e-MID.
} 
largest US home lender. Despite this, there were only marginal signs of spillover of tensions into across financial markets.

The crisis of confidence emerged at the end of July. On July 30, the German bank IKB warned of large losses related to investments in the US subprime market. A bailout by state-owned German banks followed. On August 17, another German bank, SachsenLB, became the victim of losses in asset backed securities. This generated a repricing of risk and a surge in risk aversion by investors (see ECB, 2008).

On August 9, the overnight rate rose significantly above the minimum bid rate (approximately 70 basis points) following rumours on the financial health of the Franch bank BNP Paribas. Liquidity dried up and the ECB conduced a fine tuning operation (FTO) by allotting EUR 98.84 billion in a fixed rate tender. A second FTO took place in the following day, bringing down the overnight rate by six basis points on average. The ECB intervened also on August 13, jointly with the Federal Reserve System. During the weekly main refinancing operation of August 14, the ECB allotted EUR 310 billion. On August 17, the Fed started recognizing the gravity of the situation, and cut the discount rate by 50 basis points.

After August 14, the tensions started easing in the shorter maturities, although spreads kept high by historical standard. However, the release of tensions on the lower end of the money market curve did not affect the longer maturities, with banks refusing to offer term liquidity both in the secured and in the unsecured segments. As a results, three-month Euribor rates rose from $4.22 \%$ at the beginning of August to $4.75 \%$ by the end of the month.

A number of policymakers identifies the complexity of the securitization process as the main cause of the turmoil (eg see Gonzalez-Paramo, 2008). Banks have generated a number of instrument, mainly asset backed securities and collateralised debt obligations, that has allowed them to package loans with different risk profiles, and to sell them to investors. The rationale for such instruments consists in the capability of spreading risk among a larger pool of agents. However, their intrinsic opacity has made it difficult for investors to price correctly the risk beared by the securities.

There are several reasons why the financial turmoil has hit the Euro area money market. Asset backed securities linked to US subprime loans were used in the secured segments of the market. The inability to price these assets, especially in circumstances of evaporation of liquidity, has generated distrust among banks that previously used asset backed securities as collateral. The crisis of confidence has involved the financial health of counterparties in the money market. Furthermore, it can be argued that banks have found it difficult to evaluate their own positions 
with respect to envisaged losses. Thus banks have been keen on hoarding cash for precautionary reasons in case their exposure to subprime losses would prevent from raising funds at times of need.

\section{Tests on high-frequency data}

\subsection{The measure of realized volatility}

The estimation of volatility is a key issue in financial econometrics. Standard measure of volatility based on GARCH models rely on both parametric and distributional assumptions that can hardly be tested at times. Andersen, Bollerslev and Diebold (2002) suggests a nonparametric measure that relies on the availability of high frequency data. The construction of the estimator is based on an approximating process for the price of the underlying asset in continuous time

$$
d p_{t}=\alpha_{t} d_{t}+\sigma_{t} d W_{t}
$$

where $t$ is a compact time interval, $p_{t}$ indicates the price (in logarithm), $\alpha_{t}$ is a drift term, and $W_{t}$ is a Brownian motion. I can also define a measure of integrated volatility of the price process

$$
\mathrm{IV}_{t}=\int_{0}^{t} \sigma_{t}^{2} d_{t}
$$

This equation indicates the summation of the instantaneous variance of the asset price over a time interval $t$. Hanse and Lunde (2006) suggest approximating the expression in equation 2 by using quadratic variations. Denote by $r_{t}=p_{t}-p_{t-1}$ the asset return over period $t$. Given $m$ time partitions of a trading day, integrated volatility can be approximated by realized volatility

$$
\mathrm{RV}_{i, t}^{(m)}=\sum_{j=1}^{m} r_{i, t, j}^{2}
$$

where $r_{i, t, j}^{2}$ is the intraday return over a sampling interval of length $j$. Andersen, Bollerslev and Diebold (2002) prove that $\mathrm{RV}_{i, t}^{(m)}$ converges uniformly in probability to $\mathrm{IV}_{t}$ as the time partition $m$ approaches zero. The discussion above suggests that the sampling frequency is important in obtaining a proper volatility measure. There is a tradeoff at work in this case. The higher the sampling frequency, the stronger the role of microstructure effects in the estimation of integrated volatility. However, at higher frequencies, the researcher can face the issue of missing data. Resampling tick data helps overcoming this problem, but introduces an additional source of mean 
square error. Bandi and Russell (2008) suggest using data sampled at a 5-minute frequency at most as a proper strategy.

\subsection{The dataset}

I use estimates of realized volatility for the overnight, one, three, six and twelve-month interest rates on the Euribor market. Although this paper focuses on the transmission of shocks within the longer end of the money market curve, it is important to account for the indirect channels of transmission in order to minimize the impact of model misspecification. Rates are computed from midpoints of bid-ask spread obtained from Reuters. In order to restrict the sampling to the trading hours when most of the trading takes place, intraday returns are computed on rates from $8 \mathrm{am}$ to $7 \mathrm{pm}$ CET. The number of intraday observation varies around a mean of 120 data points. The daily estimates of realized volatility for national holidays have been removed from the sample. The final dataset spans from November 112000 to March 18 2008. There are 1867 observations, out of which 1711 for the subsample until August 82007 and 157 for the subsample after August 82007.

In the following sections, I estimate a VAR model of the maturity structure of realized volatility. Given the presence of the overnight maturity, the VAR includes three exogenous variables that are related to the institutional aspects and the calendar effects present in the Euro area money market. The first variable takes the value 1 for the six days before the end of the maintenance period, when the reserve requirements become more binding, and zero otherwise. The second variable assigns the value 1 to the last day of a business month, as the uncertainty surrounding the demand for liquidity increases in this period. An additional dummy is included with the value 1 for the days when a monetary policy decision takes place.

Figure 1 plots the realized volatility (in logarithm) for the four maturities considered in the paper. Strikingly, the turmoil does not show up by simply eyeballing the figures. In fact, the dynamics of the estimated volatilities before and during the turmoil doe not differ markedly. This is also reflected in table 2, which reports some descriptive statistics. According to panels (a) and (c), the realized volatilities before the turmoil are both higher on average and more variable than that those of the turmoil period. However, the picture changes if one considers the beginning of the sharp drop in volatilities dated at the beginning of January 2006. A comparison with the period between January 12006 and August 82007 retrieves the properties of the turmoil that one would expect to see in the data, namely that the money market term structure during the turmoil displays larger variability on average. Also, the fluctuations in realized volatility are closer to the mean during the turmoil period. 


\subsection{Block-exogeneity tests}

Let the vector $x_{t}=\left[\begin{array}{lllll}o n & 1 m & 3 m & 6 m & 1 y\end{array}\right]^{\prime}$ collect the realized volatilities for the different maturities, where on denotes the overnight and the rest of the vector $x_{t}$ refers to the rest of the term structure. I assume that the shocks propagate across maturities according to the VAR in structural form

$$
A_{0} x_{t}=k+\sum_{i=1}^{q} A_{i} x_{t-i}+\epsilon_{t}
$$

This model can be rewritten in reduced form as

$$
x_{t}=k+\sum_{i=1}^{q} B_{i} x_{t-i}+u_{t}
$$

In order to give an example on the interpretation of the test, assume that there is no transmission of shocks from the 1-year segment to the rest of the maturity structure. This can be formalized as a zero restriction

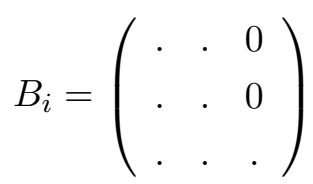

for $i=1, \ldots m$.

Block exogeneity of the 1-year maturity tests if 6 holds. This amounts to estimating an unrestricted VAR, where all the maturities enter the system, and a restricted VAR, which excludes the 1-year segment. Given the variance-covariance matrix $\Omega_{U}$ of the unrestricted model, and the variance-covariance matrix $\Omega_{R}$ of the restricted model, the likelihood ratio test statistics $L R$ can be computed

$$
L R=(T-p)\left(\log \left|\Omega_{R}\right|-\log \left|\Omega_{U}\right|\right),
$$

where $T$ is the number of observations, $p$ indicates the number of parameters of the unrestricted system, and $|\Omega|$ denotes the determinant of $\Omega$. The null hypothesis is that the block of restricted variables does not enter remaining part of the system. The test statistics is asymptotically distributed as a $\chi^{2}$ with degrees of freedom equal to the number of restrictions in the system.

\subsection{Quantile measures of comovements}

The testing framework for volatility spillovers discussed in the previous section is based on the assumption that linear VARs provide a reasonable description of the 
linkages between the volatilities of the rates at various maturities. The realized volatilities are assumed to be normally distributed, and so are their volatilities. Somehow at odds with the evidence of excess kurtosis reported in table 2, the normality assumption implies a loss of the information contained in the tails of the empirical distribution.

For these reasons, I use the semiparametric method for measuring comovements proposed by Cappiello, Gerard and Manganelli (2005). These tests allow to measure the transmission of shocks, or 'contagion', between returns by avoiding distributional assumptions. It should be stressed that, differently from available empirical literature (eg see Cappiello et al., 2006), the statistical framework of Cappiello, Gerard and Manganelli (2005) is applied to the realized volatility of the money market rates. The reason is that I am interested in the transmission of volatility spillovers, and not in the comovements between the levels of the rates.

Let $\left\{r v_{i, t}\right\}_{t=1}^{T}$ and $\left\{r v_{j, t}\right\}_{t=1}^{T}$ denote the time series of realized volatilities on two different maturities. Define by $q_{\theta, i}^{r v_{i}}$ the $\theta$-quantile of the conditional distribution of $r v_{i, t}$ at time $t . F_{t}\left(r v_{i}, r v_{j}\right)$ denotes the conditional cumulative joint distribution of the two volatilities. Finally,

$$
\begin{aligned}
& F_{t}^{-}\left(r v_{i} \mid r v_{j}\right):=\operatorname{prob}\left(r v_{i, t} \leq r v_{i} \mid r v_{j, t} \leq r v_{j}\right) \\
& F_{t}^{+}\left(r v_{i} \mid r v_{j}\right):=\operatorname{prob}\left(r v_{i, t} \geq r v_{i} \mid r v_{j, t} \geq r v_{j}\right)
\end{aligned}
$$

The conditional probability

$$
p_{t}(\theta):= \begin{cases}F_{t}^{-}\left(q_{\theta, t}^{r v_{i}} \mid q_{\theta, t}^{r v_{j}}\right) & \text { if } \theta \leq 0.5 \\ F_{t}^{+}\left(q_{\theta, t}^{r v i} \mid q_{\theta, t}^{r v_{j}}\right) & \text { if } \theta>0.5 .\end{cases}
$$

can be used to represent the characteristics of $F_{t}\left(r v_{i}, r v_{j}\right)$. In fact, $p_{t}(\theta)$ measures the probability that the volatilities at maturity $i$ are below its $\theta$-quantile, conditional on the same event occurring at maturity $j$. Since the shape of $p_{t}(\theta)$ depends on the joint distribution of the two time series, it can be derived only by numerical simulation.

The framework of Cappiello, Gerard and Manganelli (2005) can also be used to test whether the dependence between two markets has changed over time. Denote by $p^{A}(\theta):=A^{-1} \sum_{t<\tau} p_{t}(\theta)$ and $p^{B}(\theta):=B^{-1} \sum_{t<\tau} p_{t}(\theta)$ the average conditional probabilities before and after a certain event occurs at a threshold $\tau$, with $A$ and $B$ the number of corresponding observations. Let $\Delta(\underline{\theta}, \bar{\theta})$ denote the area between $p^{A}(\theta)$ and $p^{B}(\theta)$. A measure of contagion or spillovers between the two markets can 
be introduced by noting that contagion increases if

$$
\Delta(\underline{\theta}, \bar{\theta})=\int_{\underline{\theta}}^{\bar{\theta}}\left[p^{B}(\theta)-p^{A}(\theta)\right] d \theta>0
$$

It should be stressed that $\Delta(\underline{\theta}, \bar{\theta})$ allows to study changes in codependence over specific quantiles of the distribution.

Cappiello, Gerard and Manganelli (2005) show that the average conditional probability $p(\theta)$ can be estimated from the regression

$$
I_{t}^{r_{i}, r_{j}}\left(\hat{\beta}_{\theta}\right)=\alpha_{\theta}^{1}+\alpha_{\theta}^{2} D_{t}^{T}+\epsilon_{t}
$$

where hats denote estimated values, and

$$
I_{t}^{r_{i}, r_{j}}\left(\hat{\beta}_{\theta}\right):=I\left(r_{i, t} \leq q_{t}^{r_{i}}\left(\hat{\beta}_{\theta, r_{i}}\right)\right) \cdot I\left(r_{j, t} \leq q_{t}^{r_{j}}\left(\hat{\beta}_{\theta, r_{j}}\right)\right)
$$

for each $\theta$-quantile, and $D_{t}^{\tau}$ is a dummy variable for the test period $t>\tau$. The OLS estimators of the regression 12 are asymptotically consistent estimators of the average conditional probability in the two periods

$$
\begin{aligned}
\hat{\alpha}_{\theta}^{1} \stackrel{p}{\rightarrow} E\left[p_{t}(\theta) \mid \text { period } \mathrm{A}\right] & \equiv p^{A}(\theta) \\
\hat{\alpha}_{\theta}^{1}+\hat{\alpha}_{\theta}^{2} \stackrel{p}{\rightarrow} E\left[p_{t}(\theta) \mid \text { period } \mathrm{B}\right] & \equiv p^{B}(\theta)
\end{aligned}
$$

where hats denote estimates. This results also suggests a way of testing for market integration

$$
\begin{aligned}
\hat{\Delta}(\underline{\theta}, \bar{\theta}) & =(\# \theta)^{-1} \sum_{\theta \in[\underline{\theta}, \bar{\theta}]}\left[\hat{p}^{B}(\theta)-\hat{p}^{A}(\theta)\right] \\
& =(\# \theta)^{-1} \sum_{\theta \in[\underline{\theta}, \bar{\theta}]} \hat{\alpha}_{\theta}^{2},
\end{aligned}
$$

where $\# \theta$ denotes the number of terms in the summation.

\section{$5 \quad$ Results}

I estimate a VAR with the vector $x_{t}$ of endogenous variables, and with dummies for the last days of the maintenance period (lastdays), the end of the month (endm), and governing council decisions $(p c) .{ }^{5}$ For mere reasons of brevity, table 3 reports the coefficient estimates of the dummies. The first question of is interest is whether the turmoil has affected the systematic reaction of the volatilities to the institutional

\footnotetext{
${ }^{5}$ The lag length is chosen by minimizing the BIC criterion. This choice helps dealing with short sample available after August 8 2007. For the pre-turmoil model, 4 lags are used, whereas the model estimated on the turmoil sample includes 1 lag.
} 
framework.

For the pre-turmoil sample, only the volatility of the overnight rate has a statistically significant coefficient on the last days and end-of-month dummies. The overnight rate, however, does not respond to the governing council dummy. This captures the institutional pattern described earlier, and replicates one of the findings of Durré and Nardelli (2008). Interestingly, the deposit rates from one month to one year of maturity have a significant relation with the days of governing council decisions. The coefficient has a positive sign, implying that monetary policy decisions are associated with heightened uncertainty in the money market. ${ }^{6}$ As shown in panel (b) of table 3, these patterns break down after the turmoil, as none of the estimated coefficients is significant.

Additional information on systematic patterns can be obtained from the forecast error variance decomposition, reported in table $4 .^{7}$ The maturities from 6 to 12 months explain only a small fraction of the forecast error of the overnight and the 1-month rate independently from the subsample. In correspondence with the turmoil, shorter maturities carry a larger fraction of explained variance for the longer end of the money market curve (see panels (c)-(e)).

Table 5 reports the results of the block exogeneity tests before and during the turmoil. The key result is contained in the first row, which imposes the restriction that all the lags of the maturities longer than the overnight enter a regression with the Eonia rate with statistically significant coefficients. The zero $p$-values indicate rejections of the null of block exogeneity for the pre-turmoil period. This means that the volatility of the overnight rate is affected by the pooled information embodied in longer maturities. The turmoil has changed this landscape, as the volatility of the Eonia is insulated from spillovers from the longer maturities. This raises the question of the contribution of each rate to the interactions between rates.

Tables 6 displays the Wald test statistics on the lags of the restricted variables for first row of the VAR model 3, i.e. the equation for the overnight rate. Before August 9 2007, the volatility of the overnight is affected by the volatility of the 1 and 3-month rates. Again, this does not hold any longer in a turmoil world. Since the interaction between the lags of rates can account for these findings, I now turn the attention to Granger-causality $F$ tests on the entire system of equations.

The results support the previous finding that the turmoil has changed

\footnotetext{
${ }^{6}$ The reader should bear in mind that the analysis carried out in this paper disregards the effects of the communication policy of the ECB on the money market. Trichet (2008) stresses that, during the ongoing market correction, the ECB has put efforts in justifying the decisions on liquidity policy in a prompt way. Rosa and Verga (2008) uses data on the term structure of Euribor futures to show that the unexpected part of the explanation of policy decisions explains most of the variability of rates around decision dates.

${ }^{7}$ The decomposition is based on the standard Choleski decomposition.
} 
considerably the pattern of interactions between the volatility of longer term deposit and overnight rates. Before the reform, there is evidence of spillovers in volatility from the deposit rates to the overnight segment, except for the 1-year rate. With the turmoil, the overnight segment is completely insulated from movements in the volatility of the rates at longer maturities. Even more, except for one case, the evidence of spillovers across longer maturities breaks down. The increase in segmentation across the entire spectrum of maturities induced by the turmoil is counterintuitive, as it cannot account for the rise in volatility observed since August 2007.

I now turn to the tail behavior of the realized volatilities. The conditional autoregressive value-at-risk model of Engle and Manganelli (2004) is used to compute the conditional quantiles of the realized volatilities. The model takes the form

$$
q_{t}\left(\beta_{\theta}\right)=\beta_{\theta, 0}+\sum_{i=1}^{q} \beta_{\theta, i} q_{t-i}+\sum_{i=1}^{p} l\left(\beta_{\theta, j}, r v_{t-j}, \Omega_{t}\right),
$$

where $\Omega_{t}$ denotes the information set at time $t$. The autoregressive terms of the quantiles are meant to capture the clustering of volatility that is typical of financial variables. Following Cappiello, Gerard and Manganelli (2005), I estimate the time varying quantiles from the specification

$$
q_{t}\left(\beta_{\theta}\right)=\beta_{\theta, 0}+\beta_{\theta, 1} d_{t}+\beta_{\theta, 2} r v_{t-1}+\beta_{\theta, 3} q_{t-1}\left(\beta_{\theta}\right)-\beta_{\theta, 2} \beta_{\theta, 3} r v_{t-2}+\beta_{\theta, 4}\left|r v_{r-1}\right| .
$$

The dummy variable $d_{t}$ ensures that the periods of high and low volatility have the same proportion of quantile exceedances. ${ }^{8}$ Table 8 reports the results from the tests of comovements in the tails. There is no statistically significant evidence for spillovers in volatilities in the upper quantiles for any maturity. The lower tails are instead characterized by higher comovements only between volatilities of rates at longer maturities. This supports the findings from the exogeneity tests

\section{Concluding remarks}

To the best of knowledge, this paper is the first academic contribution on the impact of the financial turmoil on the Euro area money market. I present preliminary evidence on how the turmoil has affected the transmission of volatility shocks across the maturity structure. The results indicate that the longer end of the money

\footnotetext{
${ }^{8}$ In order to investigate the specification of the CAViaR model, I compute the DQ test of Engle and Manganelli (2004). This null of the DQ tests the hypothesis of no autocorrelation in the exceedances of the quantiles. The specification with unconditional quantiles is rejected over the entire domain. The test statistics are not reported for brevity.
} 
market curve has insulated itself from the shorter maturities. On the other hand, the probability of transmission of shocks between the longer maturities has increased during the turmoil.

Several points are critical for this paper. First and foremost, the findings presented here are based on the availability of a short sample for the turmoil period. Hence, as more data become available, the results might change. Second, the policy relevance of the analysis can be strengthened by considering the management of crisis carried out by the ECB. It is unclear what role the buoyant supply of liquidity through long term refinancing operations has played and, in particular, whether it could help to explain the pattern documented in this paper. 


\section{References}

Alonso, Francisco, and Roberto Blanco, "Is the volatility of the Eonia transmitted to longer-term Euro money market rates?", Working Paper, Bank of Spain, No. 0541, 2005.

Andersen, Torben, Tim Bollerslev, and Francis Diebold, "Parametric and nonparametric mesurement", NBER Working Paper, No. 279, 2002.

Bandi, Federico, and Jeffrey R. Russell (2008), "Separating microstructure noise from volatility," forthcoming in Journal of Financial Economics.

Beaupain, Renaud, and Alain Durré (2008), "The Intra- and interday patterns of the overnight market: Evidence from an electronic platform," unpublished manuscript, European Central Bank.

Cappiello, Lorenzo, Bruno Gerard, and Simone Manganelli (2005), "Measuring comovements by regression quantiles," ECB Working Paper 501.

Cappiello, Lorenzo, Bruno Gerard, Simone Manganelli, and Arjan Kadareja (2005), "Financial integration of new EU member states," ECB Working Paper 683.

Durré, Alain, and Stefano Nardelli, "Volatility in the Euro Area Money Market: Effects from the Monetary Policy Operational Framework", International Journal of Finance and Economics, 13(4), 2008, 307-322.

European Central Bank, The Monetary Policy of the ECB, 2004, 25-27.

European Central Bank, "The Volatility of the Overnight Interest Rate from a Medium-Term Perspective", Monthly Bulletin, March 2005(a), 25-27.

European Central Bank, "The Transmission of Overnight Interest Rate Volatility to Longer-Term Interest Rates in the Euro Area Money Market", Monthly Bulletin, August 2005(b), 24-26.

European Central Bank, "The Eurosystem's Operational Framework and the Volatility of the Overnight Interest Rate", Monthly Bulletin, July 2006, 25-29.

European Central Bank, "Volatility of the Overnight Interest Rate and its Transmission along the Money Market Yield Curve", Monthly Bulletin, August 2006, 26-29.

European Central Bank, "The Eurosystem's Open Market Operations during the Recent Period of Financial Market Volatility", Monthly Bulletin, May 2008, 89-104. 
Engle, Robert, and Simone Manganelli (2004), "CAViaR: Conditional Autoregressive Value at Risk by regression quantiles," Journal of Business and Economic Statistics, 22, 367-381.

Forbes, Kristin J., and Roberto Rigobon (2002), "No contagion, only interdependence: Measuring stock market comovements," Journal of Finance, $57,2223-2261$.

Hansen, Peter Reinhard, and Asger Lunde (2006), "Realized variance and market microstructure noise," Journal of Business and Economic Statistics, 24, 127-161.

Hartmann, Philippe, and Natacha Valla (2007), "The Euro money market," unpublished manuscript, European Central Bank.

Idier, Julien, and Stefano Nardelli (2008), "Probability of informed trading on the euro overnight market rate: an update," unpublished manuscript, European Central Bank.

Gonzalez-Paramo, José (2008), "Financial turmoil, securitisation and liquidity," speech at the Global ABS Conference 2008, June 1.

Rosa, Carlo, and Giovanni Verga (2008), "The impact of central bank announcements on asset prices in real time," International Journal of Central Banking, 4, 175-217.

Trichet, Jean-Claude (2007), "Hearing at the Economic and Monetary Affairs Committee of the European Parliament," Brussels, September 11.

Trichet, Jean-Claude (2008), "Reflections on the current financial markets corrections," Keynote address at the OECD Forun 2008 'Climate change, growth, stability,' Paris, June 4.

Watson, Mark (1994), "Vector Autoregressions and Cointegration," in Handbook of Econometrics, R. F. Engle and D. L. McFadden, Elsevier, 2843-2915.

Zagaglia, Paolo (2008), "The sources of volatility transmission in the Euro area money market: From longer maturities to overnight?, unpublished manuscript, Stockholm University. 


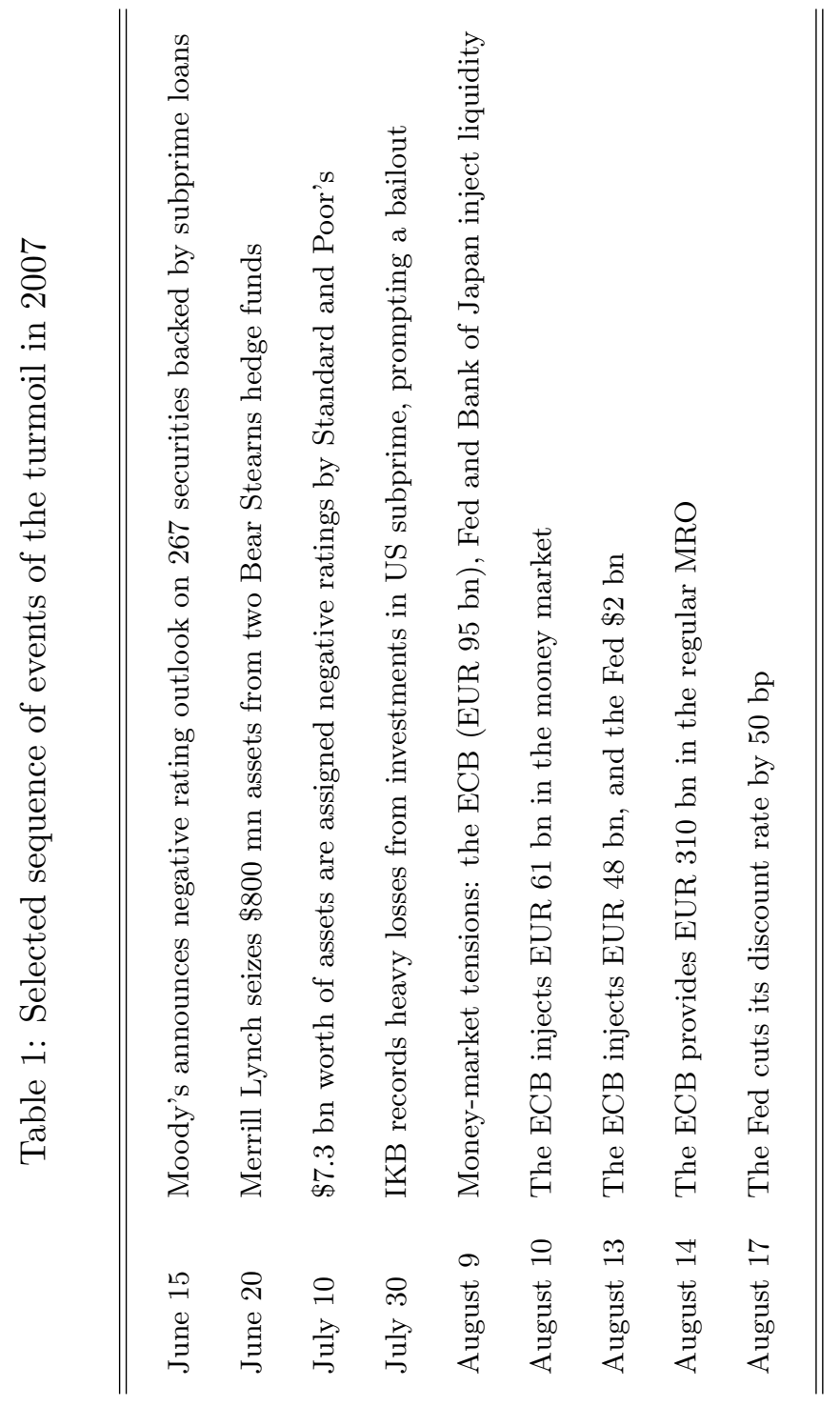


Table 2: Descriptive statistics for the realized volatilities

\begin{tabular}{lcccc}
\hline \hline & & & \\
& & & \\
& & & \\
& \multicolumn{5}{c}{ (a) Before August 92007} \\
& \multicolumn{5}{c}{} \\
\cline { 2 - 5 } & & & \\
Max & 0.77 & 0.88 & 0.79 & 0.91 \\
Min & -12.42 & -12.71 & -9.11 & -8.26 \\
Mean & -5.029 & -4.77 & -3.96 & -3.52 \\
Stand. dev. & 1.97 & 1.66 & 1.70 & 1.82 \\
Kurtosis & -0.03 & -0.40 & -0.51 & -0.48 \\
Skewness & -0.87 & -0.47 & -0.93 & -0.95 \\
& & & & \\
\hline
\end{tabular}

(b) Between December 12005 and August 82007

\begin{tabular}{lcccc} 
& & & & \\
\cline { 2 - 5 } Max & -3.66 & 0.828 & -2.86 & -2.76 \\
Min & -12.43 & -11.16 & -9.11 & -8.26 \\
Mean & -7.8 & -6.63 & -6.64 & -6.42 \\
Stand. dev. & 1.29 & 1.13 & 0.83 & 0.87 \\
Kurtosis & 1.13 & 6.92 & 7.15 & 6.33 \\
Skewness & 0.09 & 1.28 & 2.11 & 2.22 \\
& & & & \\
\hline
\end{tabular}

(c) From August 92007

\begin{tabular}{lcccc} 
& & & & \\
Max & -3.95 & -0.18 & -1.43 & -2.75 \\
Min & -9.01 & -7.03 & -7.75 & -6.62 \\
Mean & -6.35 & -5.33 & -5.62 & -5.27 \\
Stand. dev. & 0.79 & 0.85 & 0.65 & 0.59 \\
Kurtosis & 0.66 & 7.74 & 10.89 & 1.39 \\
Skewness & -0.34 & 1.53 & 1.59 & 0.76 \\
& & & & \\
\hline \hline
\end{tabular}

Legend: This table reports the descriptive statistics for different relevant subsamples of the realized volatilities. 
Table 3: Selected parameter estimates from the VAR model

\begin{tabular}{ccccccc}
\hline \hline on & $m 1$ & $m 3$ & $m 6$ & $y 1$ \\
\hline
\end{tabular}

(a) Before August 92007

\begin{tabular}{lccccc} 
& & & & & \\
lastdays & 1.141 & 0.052 & 0.027 & -0.015 & -0.006 \\
& $(0.057)$ & $(0.050)$ & $(0.052)$ & $(0.033)$ & $(0.031)$ \\
endm & & & & & \\
& $\begin{array}{c}0.893 \\
(0.110)\end{array}$ & $\begin{array}{c}-0.053 \\
(-0.551)\end{array}$ & $\begin{array}{c}-0.089 \\
(0.100)\end{array}$ & $\begin{array}{c}0.002 \\
(0.063)\end{array}$ & $\begin{array}{c}-0.039 \\
(0.061)\end{array}$ \\
& & & & & \\
& -0.061 & 0.388 & 0.362 & 0.239 & 0.173 \\
& $(0.111)$ & $(0.098)$ & $(0.100)$ & $(0.064)$ & $(0.061)$ \\
& & & & & \\
& & & & & \\
\hline
\end{tabular}

(b) From August 92007

\begin{tabular}{lccccc} 
& \multicolumn{7}{c}{} \\
\cline { 2 - 6 } lastdays & 0.071 & 0.229 & 0.248 & 0.197 & 0.071 \\
& $(0.176)$ & $(0.157)$ & $(0.176)$ & $(0.141)$ & $(0.127)$ \\
endm & 0.109 & -0.031 & -0.307 & -0.134 & -0.055 \\
& $(0.325)$ & $(0.289)$ & $(0.325)$ & $(0.259)$ & $(0.234)$ \\
$p c$ & & & & \\
& 0.167 & -0.436 & -0.252 & -0.439 & -0.074 \\
& $(0.324)$ & $(0.289)$ & $(0.325)$ & $(0.259)$ & $(0.234)$ \\
\hline \hline
\end{tabular}

Legend: Standard errors are reported within brackets. The models are estimated on daily data for realized volatility and dummies for last days, end of maintenance period and governing council decision. The order of the VAR is selected through the Bayesian-Schwartz criterion. The variables read as follow: on realized volatility on the overnight, $1 m$ realized volatility on the 1 -month Euribor rate, $3 m$ realized volatility on the 3-month Euribor rate, $6 \mathrm{~m}$ realized volatility on the 6 -month Euribor rate, $1 y$ realized volatility on the 1-year Euribor rate. 


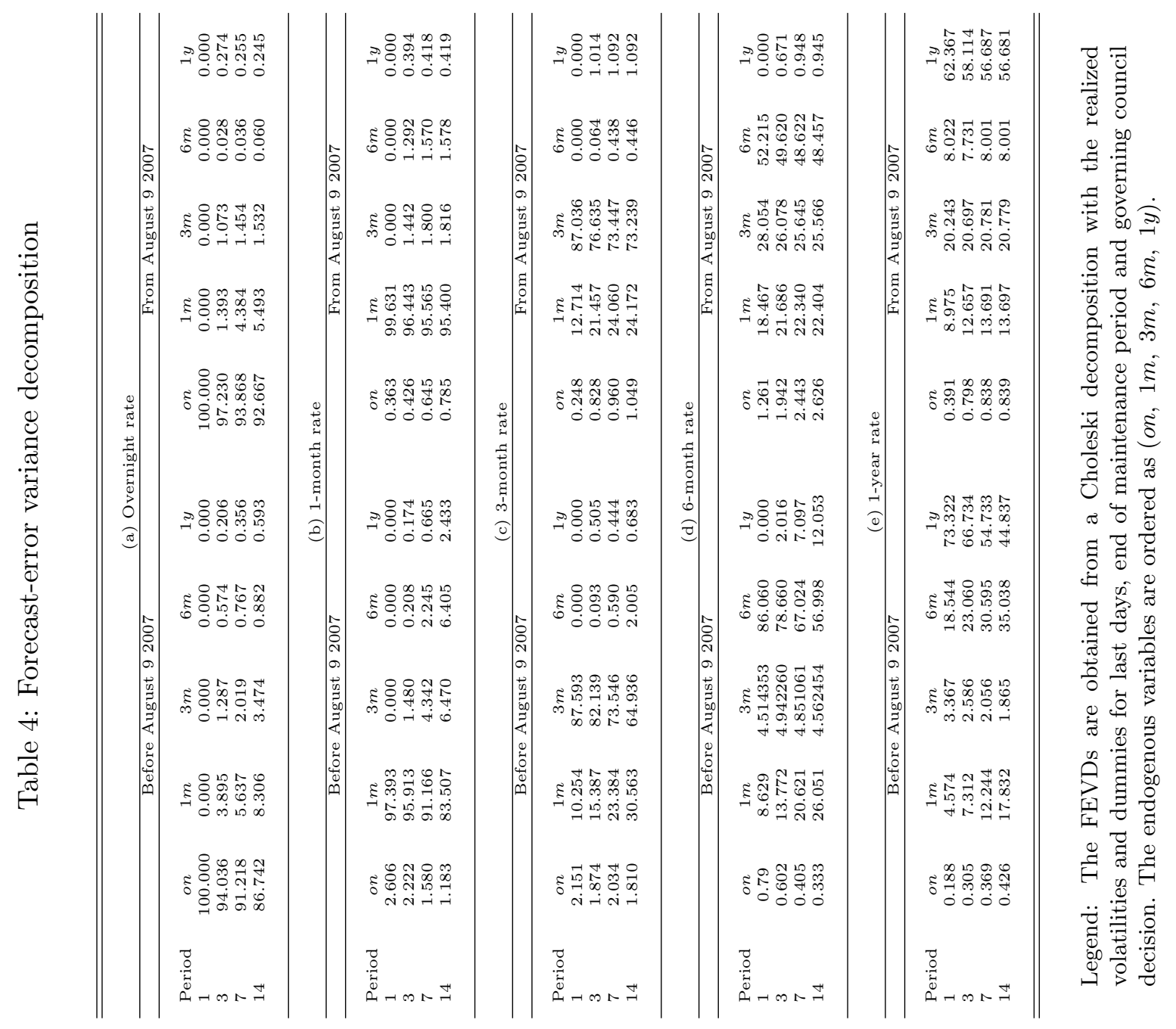


Table 5: Block-exogeneity LR tests, on as a dependent variable Restrictions $\quad$ Before August 92007 From August 92007

$\begin{array}{lcc}{[m 1, m 3, m 6, y 1]} & 78.34 & 2.86 \\ & (0.0) & (0.58) \\ & & \\ & 6084.20 & 1.33 \\ & (0.0) & (0.71) \\ & & \\ & 5275.81 & 0.02 \\ (m 6, y 1] & (0.0) & (0.98)\end{array}$

Legend: This table reports the test statistics and the $p$-values (in brackets) from the tests of block exogeneity. The tests are computed on vector autoregressions on daily data for realized volatility and dummies for last days, end of maintenance period and governing council decision. The orders of the VARs are selected through the Bayesian-Schwartz criterion. The variables read as follow: on realized volatility on the overnight, $1 \mathrm{~m}$ realized volatility on the 1-month Euribor rate, $3 \mathrm{~m}$ realized volatility on the 3-month Euribor rate, $6 \mathrm{~m}$ realized volatility on the 6 -month Euribor rate, $1 y$ realized volatility on the 1-year Euribor rate. 
Table 6: Block-exogeneity Wald tests, on as a dependent variable

\begin{tabular}{ccc}
\hline \hline Restrictions & Before August 9 2007 & From August 9 2007 \\
& & \\
\hline$[y 1]$ & 4.406 & 0.542 \\
& $(0.221)$ & $(0.76)$ \\
& 4.732 & 0.478 \\
{$[m 6]$} & $(0.192)$ & $(0.78)$ \\
& & 1.193 \\
{$[m 3]$} & $\begin{array}{c}14.531 \\
(0.002)\end{array}$ & $(0.55)$ \\
& & 0.542 \\
{$[m 1]$} & 25.927 & $(0.76)$ \\
& $(0.0)$ & \\
\hline \hline
\end{tabular}

Legend: The tests are computed on the first equation of a vector autoregression on daily data for realized volatility and dummies for last days, end of maintenance period, and governing council decision. The table reports $\chi^{2}$ test statistics and $p$-values (in brackets). The variables of the VAR are ordered as follows: on realized volatility on the overnight, $1 m$ realized volatility on the 1-month Euribor rate, $3 m$ realized volatility on the 3-month Euribor rate, $6 m$ realized volatility on the 6 -month Euribor rate, $1 y$ realized volatility on the 1-year Euribor rate. 
Table 7: Granger-causality $F$ tests

\begin{tabular}{|c|c|c|c|c|c|c|c|c|}
\hline & \multicolumn{4}{|c|}{ Before August 92007} & \multicolumn{4}{|c|}{ From August 92007} \\
\hline & $1 y$ & $6 m$ & $3 m$ & $1 m$ & $1 y$ & $6 m$ & $3 m$ & $1 m$ \\
\hline & \multicolumn{4}{|c|}{ does not Granger-cause } & \multicolumn{4}{|c|}{ does not Granger-cause } \\
\hline on & $\begin{array}{l}2.148 \\
(0.092)\end{array}$ & $\begin{array}{l}5.951 \\
(0.0005)\end{array}$ & $\begin{array}{c}12.236 \\
(6 e-8)\end{array}$ & $\begin{array}{c}11.423 \\
(2 e-7)\end{array}$ & $\begin{array}{l}0.789 \\
(0.456)\end{array}$ & $\begin{array}{l}1.226 \\
(0.296)\end{array}$ & $\begin{array}{l}1.948 \\
(0.141)\end{array}$ & $\begin{array}{l}1.211 \\
(0.301)\end{array}$ \\
\hline $1 y$ & & $\begin{array}{l}15.272 \\
(8 e-10)\end{array}$ & $\begin{array}{l}1.354 \\
(0.255)\end{array}$ & $\begin{array}{c}6.629 \\
(0.0002)\end{array}$ & & $\begin{array}{l}0.652 \\
(0.522)\end{array}$ & $\begin{array}{l}0.924 \\
(0.399)\end{array}$ & $\begin{array}{l}3.642 \\
(0.029)\end{array}$ \\
\hline $6 m$ & $\begin{array}{l}24.293 \\
(2 e-15)\end{array}$ & & $\begin{array}{l}2.727 \\
(0.043)\end{array}$ & $\begin{array}{c}10.945 \\
(4 e-7)\end{array}$ & $\begin{array}{l}0.629 \\
(0.534)\end{array}$ & & $\begin{array}{l}0.434 \\
(0.649)\end{array}$ & $\begin{array}{l}2.086 \\
(0.128)\end{array}$ \\
\hline $3 m$ & $\begin{array}{l}17.114 \\
(6 e-11)\end{array}$ & $\begin{array}{l}16.663 \\
(1 e-10)\end{array}$ & & $\begin{array}{l}26.774 \\
(7 e-17)\end{array}$ & $\begin{array}{l}0.580 \\
(0.581)\end{array}$ & $\begin{array}{l}1.421 \\
(0.245)\end{array}$ & & $\begin{array}{c}9.707 \\
(0.0001)\end{array}$ \\
\hline $1 m$ & $\begin{array}{l}18.955 \\
(4 e-12)\end{array}$ & $\begin{array}{l}25.469 \\
(4 e-16)\end{array}$ & $\begin{array}{c}12.118 \\
(8 e-8)\end{array}$ & & $\begin{array}{l}1.353 \\
(0.261)\end{array}$ & $\begin{array}{l}0.652 \\
(0.522)\end{array}$ & $\begin{array}{l}1.799 \\
(0.169)\end{array}$ & \\
\hline
\end{tabular}

Legend: The tests are computed on a vector autoregression on daily data for realized volatility and dummies for last days, end of maintenance period, and governing council decision. The table reports $F$ test statistics and $p$-values (in brackets). The variables read as follow: on realized volatility on the overnight, $1 \mathrm{~m}$ realized volatility on the 1-month Euribor rate, $3 m$ realized volatility on the 3 -month Euribor rate, $6 m$ realized volatility on the 6-month Euribor rate, $1 y$ realized volatility on the 1-year Euribor rate. 
Table 8: Test of difference in tail co-incidences before and after August 82007

\begin{tabular}{lcccc}
\hline \hline \multirow{2}{*}{ Maturity } & \multicolumn{3}{c}{ Lower tail: $\theta \leq 0.5$} & \multicolumn{2}{c}{ Higher tail: $\theta \geq 0.5$} \\
& \multicolumn{3}{c}{$\hat{\delta}(0,0.5)$} & \multicolumn{2}{c}{$\hat{\delta}(0.5,1)$} \\
& Stat. & s.e. & Stat. & s.e. \\
\cline { 2 - 5 } & & & & \\
& & & & \\
1-month - 3-month & 7.49 & 4.11 & 1.39 & 3.57 \\
1-month - 6-month & 6.24 & 3.36 & -2.26 & 2.77 \\
1-month - 1-year & 3.06 & 3.35 & -1.11 & 2.98 \\
3-month - 6-month & 14.73 & 4.35 & 1.22 & 3.76 \\
3-month - 1-year & 10.84 & 4.24 & -0.89 & 3.49 \\
6-month - 1-year & 10.46 & 5.16 & -2.67 & 4.05 \\
\hline \hline
\end{tabular}


Figure 1: Realized volatilities (in logs)
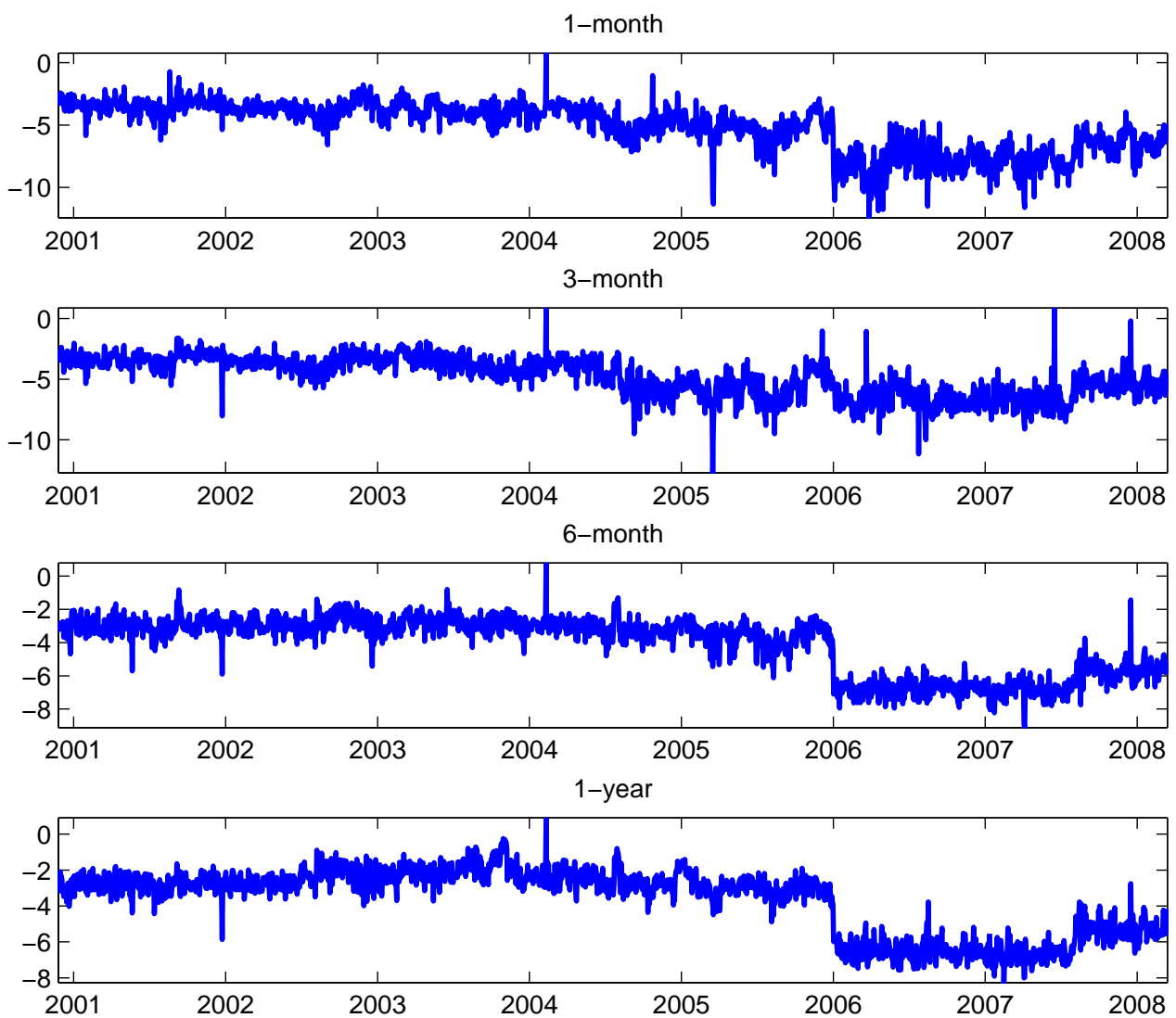